\title{
Enzymatic Synthesis of Therapeutic Nucleosides using a Highly Versatile Purine Nucleoside 2'-DeoxyribosylTransferase from Trypanosoma brucei
}

\author{
Elena Pérez, ${ }^{[a]}$ Pedro A. Sánchez-Murcia, ${ }^{[b]}$ Justin Jordaan, ${ }^{[c, d]}$ María Dolores Blanco, ${ }^{[e]}$ \\ José Miguel Mancheño, ${ }^{[f]}$ Federico Gago, ${ }^{\left[{ }^{[g]}\right.}$ and Jesús Fernández-Lucas ${ }^{*[a, h]}$
}

\begin{abstract}
The use of enzymes for the synthesis of nucleoside analogues offers several advantages over multistep chemical methods, including chemo-, regio- and stereoselectivity as well as milder reaction conditions. Herein, the production, characterization and utilization of a purine nucleoside 2'-deoxyribosyltransferase (PDT) from Trypanosoma brucei are reported. TbPDT is a dimer which displays not only excellent activity and stability over a broad range of temperatures $\left(50-70^{\circ} \mathrm{C}\right), \mathrm{pH}(4-7)$ and ionic strength $(0-500 \mathrm{mM} \mathrm{NaCl})$ but also an unusual high stability under alkaline conditions ( $\mathrm{pH} 8-10)$. TbPDT is shown to be proficient in the biosynthesis of numerous therapeutic nucleosides, including didanosine, vidarabine, cladribine, fludarabine
\end{abstract}

and nelarabine. The structure-guided replacement of Val11 with either Ala or Ser resulted in variants with 2.8-fold greater activity. TbPDT was also covalently immobilized on glutaraldehyde-activated magnetic microspheres. MTbPDT3 was selected as the best derivative ( $4200 \mathrm{IU} / \mathrm{g}$, activity recovery of $22 \%$ ), and could be easily recaptured and recycled for $>25$ reactions with negligible loss of activity. Finally, MTbPDT3 was successfully employed in the expedient synthesis of several nucleoside analogues. Taken together, our results support the notion that TbPDT has good potential as an industrial biocatalyst for the synthesis of a wide range of therapeutic nucleosides through an efficient and environmentally friendly methodology. [a] Dr. E. Pérez, Dr. J. Fernández-Lucas

Applied Biotechnology Group

Universidad Europea de Madrid

Villaviciosa de Odón E-28670 (Spain)

E-mail: jesus.fernandez2@universidadeuropea.es

[b] Dr. P. A. Sánchez-Murcia

Institute of Theoretical Chemistry

Faculty of Chemistry

University of Vienna

Vienna 1090 (Austria)

[c] Dr. J. Jordaan

Biotechnology Innovation Centre

Rhodes University

Grahamstown 6140 (South Africa)

[d] Dr. J. Jordaan

ReSyn Biosciences

Meiring Naudé Road

Brummeria

Pretoria 0184 (South Africa)

[e] Dr. M. D. Blanco

Department of Biochemistry and Molecular Biology III

School of Medicine

Universidad Complutense

Madrid E-28040 (Spain)

[f] Dr. J. M. Mancheño

Department of Crystallography and Structural Biology

Rocasolano Institute (CSIC)

Madrid E-28006 (Spain)

[g] Prof. F. Gago

Department of Biomedical Sciences and "U. A. IQM-CSIC"

School of Medicine and Health Sciences

University of Alcalá

Alcalá de Henares E-28805 (Spain)

[h] Dr. J. Fernández-Lucas

Grupo de Investigación en Desarrollo Agroindustrial Sostenible Universidad de la Costa

Barranquilla 080002 (Colombia)

Supporting information for this article is available on the WWW under https://doi.org/10.1002/cctc.201800775

\section{Introduction}

Nucleosides are known to be ubiquitous molecules in crucial biochemical processes including genetic information storage and transfer. There are many examples in the literature of nucleoside analogues that are therapeutically used as antimicrobial, antiviral and anticancer agents or employed as starting materials for the preparation of antisense oligonucleotides. ${ }^{[1]}$ These molecules have been traditionally synthesized by different chemical methods through multistep processes that require protection and de-protection reactions as well as isolation of intermediates. ${ }^{[2]}$ In contrast, the enzymatic synthesis of nucleoside analogues is an alternative that shows many advantages, such as (i) high chemo-, regio- and stereoselectivity, (ii) the possibility of being achieved in one-pot, one-step reactions under mild conditions, and (iii) use of an environmentally friendly technology. ${ }^{[3]}$

Nucleoside 2'-deoxyribosyltransferases (NDTs) have been generally employed in the synthesis of nucleosides because they catalyze the exchange of 2'-deoxyribose between purine and/or pyrimidine bases. ${ }^{[3 \mathrm{~b}, 4]}$ According to their substrate specificity, NDTs have been classified as type I, which transfer the glycosyl moiety from purine 2'-deoxyribonucleosides to purine bases (Pur $\leftrightarrow$ Pur) such as adenine $\mathbf{1}$, guanine $\mathbf{2}$ or hypoxanthine 3 (Figure 1), and type II, which also accept pyrimidines as substrates (Pur $\leftrightarrow$ Pur, Pur $\leftrightarrow P y r, P y r \leftrightarrow P y r$ ). ${ }^{[3 b, 4-5]}$ For this reason, type I NDTs are also known as purine-nucleoside 2'-deoxyribosyltransferases (PDTs). Both type I and type II NDTs are (i) specific for 2'-deoxyribonucleosides, (ii) regioselective ( $\mathrm{N}-1$ and $\mathrm{N}-9$ glycosylation in pyrimidines and purines, respectively), and (iii) stereoselective ( $\beta$-anomers are exclusively 
formed). However, some studies have shown that NDTs can tolerate modifications at $\mathrm{C}^{\prime}$ and $\mathrm{C}^{\prime}$ of the $2^{\prime}$-deoxyribose sugar. $^{[3 b, 4,6]}$

Despite the advantages of enzyme-mediated bioconversions, their application in industry is limited by several factors, including: i) the high cost of recombinant enzymes, ii) the low stability and short lifespan of the enzyme subjected to the rather harsh conditions often needed in some industrial processes, and iii) difficulties in the isolation of the biocatalyst from the reaction medium for reutilization. Enzyme immobilization may overcome these problems by enhancing protein stability, facilitating separation of products, and allowing the biocatalyst to be reused in various reactor configurations. In this area, our research group has been largely involved in the development of immobilized biocatalysts for the synthesis of therapeutic nucleoside analogues. ${ }^{[3 b, 4 b, 7]}$ Recently, enzyme binding to magnetic supports has emerged as an alternative method that provides immobilized biocatalysts which are easily separated from the reaction medium by applying a magnetic field. ${ }^{[7-8]}$ Moreover, these magnetic biocatalysts can be employed in fluidized bed reactors, which are stabilized by a magnetic field, or in magnetic rod-driven stirred tank reactors, in which deterioration of the biocatalyst due to mechanical agitation is avoided (Figure 1).

In our search for PDTs suitable as biocatalysts for the synthesis of non-natural therapeutic nucleosides, we found a good candidate in an uncharacterized protein encoded in the genome of Trypanosoma brucei (TbPDT) that shares 67\% sequence identity with a previously reported PDT from Leishmania mexicana (LmPDT). ${ }^{[9]}$ The putative enzyme was produced and characterized using both biophysical and biochemical methods. Studying the effects of $\mathrm{pH}$, temperature and ionic strength on enzyme activity and stability allowed us to select a set of optimal operative conditions for the synthesis, in aqueous media, of several nucleoside analogues with therapeutic application (4-10 in Figure 2). In addition, structure-guided site-directed mutagenesis studies led us to produce two TbPDT variants which showed enhanced activity over that of the wild-type enzyme in the synthesis of 2'-deoxyadenosine. Finally, to explore its potential as a biocatalyst, TbPDT was immobilized onto magnetic microspheres, which were physically characterized by scanning electron microscopy (SEM) and dynamic light scattering (DLS).

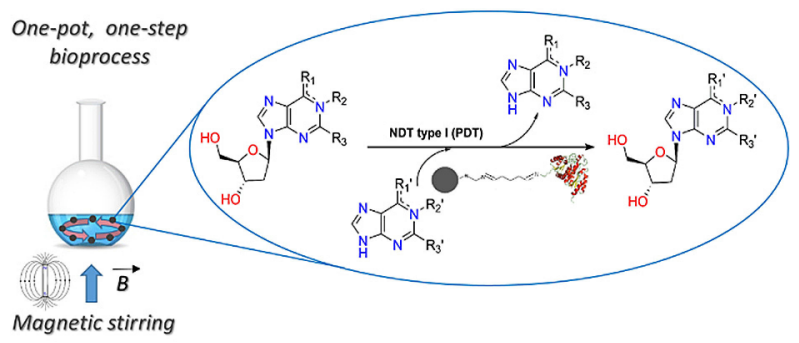

Figure 1. Enzymatic synthesis of nucleosides by 2'-deoxyribosyltransferase immobilized on magnetic microspheres.

\section{Results and Discussion}

\section{Production and Purification of TbPDT}

The pdt gene of Trypanosoma brucei, annotated as encoding a putative 2'-deoxyribosyltransferase, was cloned and overexpressed in E. coli BL21 (DE3). The recombinant $\mathrm{N}$-terminal His ${ }_{6}^{-}$ tagged TbPDT was purified by using two chromatographic steps. SDS-PAGE analysis of the purified enzyme showed a single protein band with an apparent molecular mass of $19 \mathrm{kDa}$ (Figure S1, Supporting Information). $\mathrm{N}$-terminal $\mathrm{His}_{6}$-tagged TbPDT was predicted to contain 169 amino acid residues and to possess a relative molecular mass of $19.09 \mathrm{kDa}$ (Protparam, http://web.expasy.org/protparam). These results agree with those described by Bosch et al. ${ }^{[10]}$ who reported the crystal structure of the same protein but did not carry out any functional characterization that could support its activity as a true NDT.

Sedimentation velocity experiments reveal TbPDT as a single species with an experimental sedimentation coefficient of $3.17 \mathrm{~S}\left(\mathrm{~s}_{20, \mathrm{w}}=3.19\right)$ compatible with an obligate homodimer of $39.07 \mathrm{kDa}$ molecular weight. Thus, the single monomer affords a value of $19.53 \mathrm{kDa}$, which is very close to the molecular mass calculated from the amino acid sequence $(19.09 \mathrm{kDa})$. In this respect, different oligomeric states have been described for various bacterial and protozoan NDTs. On the one hand, NDTs from Lactobacillus leichmanii, L. helveticus (LhNDT) and L. reuteri (LrNDT) appear as hexamers (displaying a molecular weight ranging from 105 to $120 \mathrm{kDa}){ }^{[4,11]}$ whereas a type II NDT from Lactococcus lactis was characterized as a tetramer of $69 \mathrm{kDa} .^{[12]}$ On the other hand, we recently reported $L$ mPDT as a dimer ${ }^{[9]}$ whose activity is similar to that of its bacterial counterparts (Table 1). These findings support the view that a higher oligomerization state for NDTs is not essential for catalysis and/ or stabilization of the active conformation.

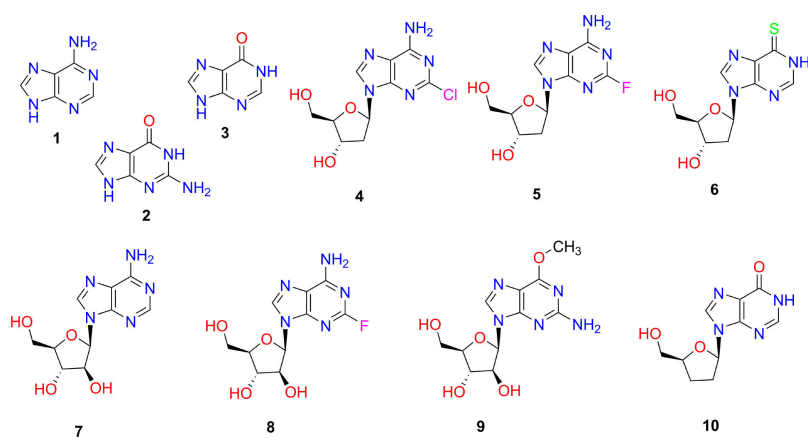

Figure 2. Chemical structures of the most energetically stable tautomeric forms of (i) purine bases adenine (1), guanine (2) and hypoxanthine (3), (ii) 2'-deoxyribonucleosides cladribine (4), 2F-dAdo (5) and 6-MPdRib (6), (iii) arabinosyl nucleosides vidarabine (7), fludarabine (8) and nelarabine (9), and (iv) 2',3'-dideoxyinosine (10). 


\begin{tabular}{|c|c|c|c|c|c|c|c|c|c|c|c|c|}
\hline \multirow[b]{2}{*}{ Acceptor ${ }^{[b]} /$ Donor } & \multicolumn{3}{|c|}{ TbPDT } & \multicolumn{6}{|c|}{ Specific activity (IU/mg protein) } & \multicolumn{3}{|c|}{$\operatorname{LmPDT}^{[a]}$} \\
\hline & Ade & Gua & Hyp & Ade & Gua & Hyp & Ade & Gua & Hyp & Ade & Gua & Hyp \\
\hline dAdo & - & $10.5 \pm 2.3$ & $9.5 \pm 2.4$ & - & n.d. & 0.06 & - & 0.09 & 0.02 & - & 13.8 & 75.4 \\
\hline dGuo & $21.4 \pm 3.1$ & - & $39.0 \pm 2.6$ & 0.05 & - & 0.05 & 0.08 & - & 0.02 & 52.7 & - & 68.6 \\
\hline dlno & $38.5 \pm 3.3$ & $11.0 \pm 2.1$ & - & 0.08 & n.d. & - & 0.04 & 0.04 & - & 73.1 & 14.5 & - \\
\hline
\end{tabular}

[a] Activities for $L h N D T, B b P D T$ and $L m P D T$ were taken from Refs. [4a], [5] and [9], respectively; [b] reaction conditions were $0.3 \mu \mathrm{g}$ of enzyme in $40 \mu \mathrm{L}$ at $50^{\circ} \mathrm{C}$ for $5 \mathrm{~min}$. Ade and Hyp concentrations were $10 \mathrm{mM}$ in $50 \mathrm{mM}$ sodium phosphate buffer, pH 6.0, whereas that of Gua was $1 \mathrm{mM}$ in 50 mM borate buffer, pH 8.5; n.d.: not detected.

\section{Biochemical Characterization of TbPDT}

TbPDT is highly active ( $>63 \%$ ) across a broad temperature range (from 50 to $70^{\circ} \mathrm{C}$ ), with an optimum at $60^{\circ} \mathrm{C}$ (Figure $3 \mathrm{~A}$ ). The $\mathrm{pH}$ profile reveals that TbPDT is more than $60 \%$ active over a broad $\mathrm{pH}$ range (from 4 to 7 ) and displays maximum activity at a pH between 5 and 6 (Figure 3B). In addition, negligible loss of activity is observed in the presence of $500 \mathrm{mM} \mathrm{NaCl}$, and only a slight decrease is observed when this concentration is increased (i.e. $70 \%$ activity remains at $1 \mathrm{M} \mathrm{NaCl}$ ) (Figure $3 \mathrm{C}$ ).

The effect of $\mathrm{pH}$ on TbPDT stability was evaluated by incubating the enzyme for $30 \mathrm{~h}$ at $50^{\circ} \mathrm{C}$ at different $\mathrm{pH}$ values (ranging from 6.5 to 10). The results suggest that alkaline environments $(\mathrm{pH} 8-10)$ do not inactivate the enzyme during this time period to a significant extent (Figure 3D). This unusual tolerance to alkaline conditions was unexpected for a mesophilic enzyme and is a very interesting advantage for enzyme immobilization, as will be described below.

The stability of TbPDT as a biocatalyst was assessed by showing that the enzyme stored at $4{ }^{\circ} \mathrm{C}$ still displays $85 \%$ relative activity after 180 days (data not shown). Nonetheless, this percentage drops to $\sim 23 \%$ when TbPDT is stored at $-20^{\circ} \mathrm{C}$ or $-80^{\circ} \mathrm{C}$.
A

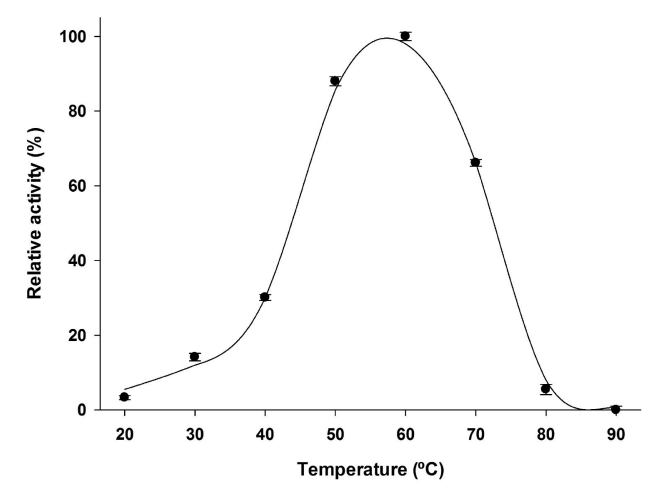

C

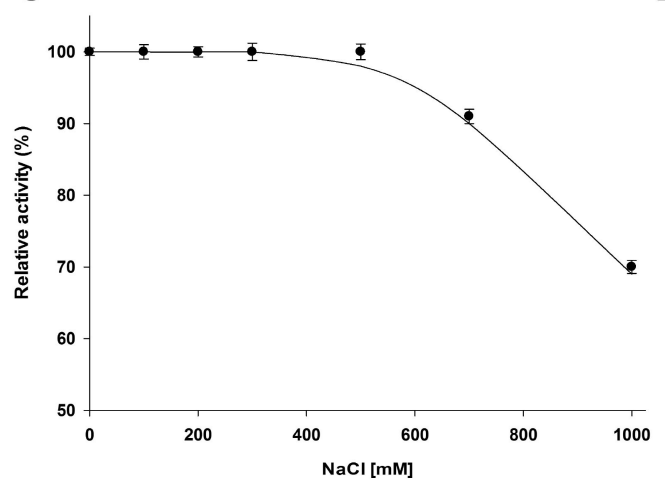

B

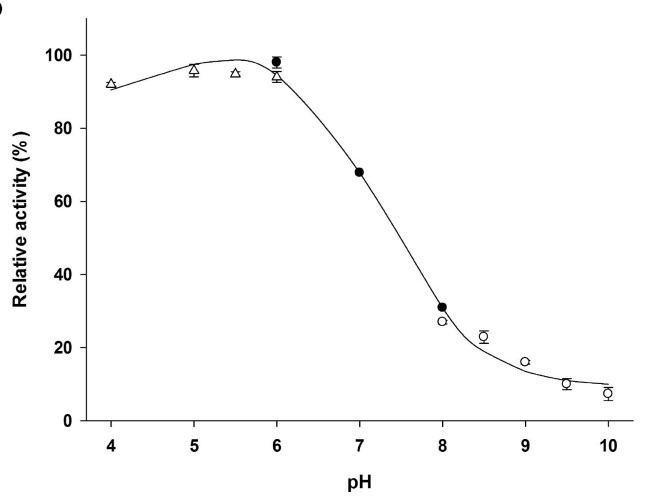

D

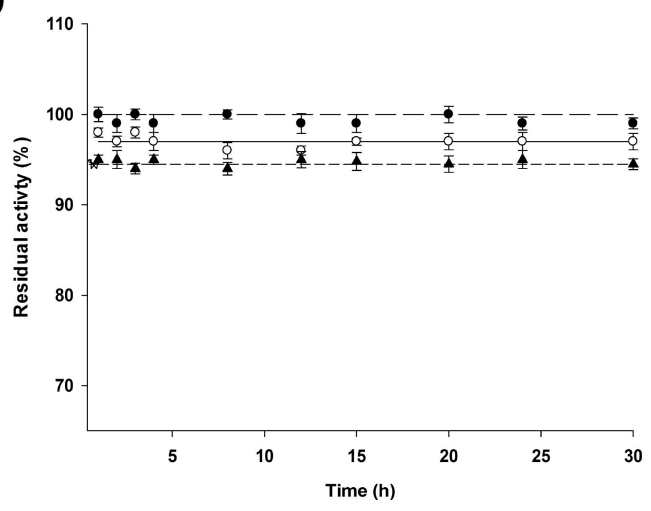

Figure 3. Dependence of TbPDT activity and stability on $\mathrm{pH}$ and temperature. A) Effect of temperature on TbPDT activity. B) Effect of pH on TbPDT activity, ( $\triangle$ ) sodium citrate $50 \mathrm{mM}(\mathrm{pH} 4-6),(\bigcirc)$ sodium phosphate $50 \mathrm{mM}(\mathrm{pH} \mathrm{6-8),} \mathrm{(O)} \mathrm{sodium} \mathrm{borate} 50 \mathrm{mM}(\mathrm{pH} 8-10)$. C) Effect of ionic strength on TbPDT activity, and D) Time course of the thermal inactivation of $\mathrm{TbPDT}$ at $50^{\circ} \mathrm{C}$ in $10 \mathrm{mM}$ sodium phosphate $\mathrm{pH} 6.5(\mathbf{O})$, and $10 \mathrm{mM}$ sodium borate $\mathrm{pH} 8(\mathrm{O})$ and $\mathrm{pH} 10(\mathbf{\Delta})$ 


\section{Substrate Specificity and Structural Considerations}

Our experimental data show that TbPDT should be classified as a type I NDT since it exclusively catalyzes the transfer of 2'deoxyribose between purine bases. In common with other previously described PDTs, ${ }^{[4 a, 5,9]}$ TbPDT recognizes 2'-deoxyinosine (dlno) and hypoxanthine (Hyp) as the best nucleoside donor and base acceptor, respectively (Table 1).

Because type II NDTs offer several advantages over PDTs, such as higher activity values under the same experimental conditions or the possibility of using a broad range of substrates, type II NDTs usually represent the best option for the enzymatic synthesis of nucleoside analogues. Nevertheless, the specific activities of TbPDT are higher than those reported for other PDTs from Lactobacillus and Borrelia species under similar enzymatic assay conditions (Table 1) and comparable to those previously described for several type II NDTs from Lactobacillus reuteri ${ }^{[4 b]}$ and Lactobacillus delbrueckii. ${ }^{[13]}$ TbPDT can also use as substrates the manifold of purine derivatives and nucleoside analogues displayed in Tables 2 and 3, and it is to be preferred, in principle, over $\operatorname{LmPDT}^{[9]}$ because it can transglycosylate on a larger number of purine analogues when dlno is used as the donor nucleoside (data not shown). These results encouraged us to consider TbPDT a good candidate for the enzymatic synthesis of nucleoside analogues.

TbPDT is a homodimer which displays the typical 2'deoxyribose binding site motif made up of two acidic residues from one subunit (Asp76 and Glu82) and one polar residue from the characteristic NLM motif in the neighboring monomer (Asn126\#). The 5'-hydroxyl group of the incoming 2'-deoxynucleoside hydrogen bonds to the carboxylate of Asp76 and is hydrogen bonded by the carboxamide of Asn126\#. The nucleophilic attack on $\mathrm{C}^{\prime}$ ' of the sugar is effected by the sidechain carboxylate of Glu82, which is held in position by hydrogen bonds donated by the phenol group of Tyr5 and the 3 '-hydroxyl of the sugar (Figure 4). In the near-attack conformation, ${ }^{[14]}$ one of the lone pairs of the M128\# sulfur is poised to interact with the developing positive charge on the oxocarbenium ion of the transition state. The purine ring is sandwiched between the hydrophobic side chains of Val11 and Phe12, on one side, and those of Ile49 and Leu127\# on the other side, whereas the nucleobase's $\mathrm{N}-3$ atom is recognized by the carboxamide nitrogen of Asn53. This is a rather unique feature of PDTs from trypanosomatids (family Trypanosomatidae), as recently reported for $\mathrm{LmPDT}^{\left[{ }^{[9]}\right.}$ because NDTs from Lactobacillus have an aspartic acid at the equivalent position, which means that this side chain needs to be protonated as a carboxylic acid. $^{[15]}$ The occurrence of Asn53 in TbPDT (and Asn56 in LmPDT) in a position usually occupied by Asp in other NDTs may be advantageous for resilience at high $\mathrm{pH}$ values.

The results of our molecular dynamics (MD) simulations reveal that, in the Michaelis complex (Figure $4 \mathrm{~B}$ ), the flexible ${ }^{39}$ TDNEATEA ${ }^{46}$ and ${ }^{116}$ LRVEGF $^{121}$ loops connecting $\beta 2-\alpha 3$ and $\beta 6-$ $\alpha 6$, respectively, become more ordered because of the involvement of the side chain of Glu42 in base recognition (Figure 4A) and the stacking of the phenyl ring of Phe121\# on lle49 and Leu127\#, which results in the approximation of Glu119\# towards the N-7 position of the base. In this "closed" conformation, the substrate is placed within a preorganized active site in an orientation conducive to reaction. Thereafter, we postulate that glycosydic bond cleavage by nucleophilic attack of Glu82 on C1' is accompanied by proton transfer from Glu119\# to N-7 so that this tautomer is initially generated, in agreement with early data ${ }_{1}^{[16]}$ prior to departure of the energetically more stable $\mathrm{N}-9$ tautomer. ${ }^{[17]}$

To understand the structural determinants of TbPDT stabilization, the dimer interface was analyzed with the aid of programs MM-ISMSA ${ }^{[18]}$ and HBplot, ${ }^{[19]}$ which provided valuable information about those residues that contribute the most to stabilizing the dimer. The former dissected, on a per-residue basis, the monomer-monomer binding energy (Figure 5), including desolvation, and the latter analyzed the types of hydrogen bonds (backbone-backbone, side chain-backbone, and side chain-side chain) between the two monomers (Figure S2). Our analyses reveal the importance of Phe12, Arg50, Arg71, Phe81, Leu116, Arg117, and Met128 for dimer stabilization. In this respect, it is noteworthy that Arg71 is part of an insertion particular to trypanosomatids that is located in a
A

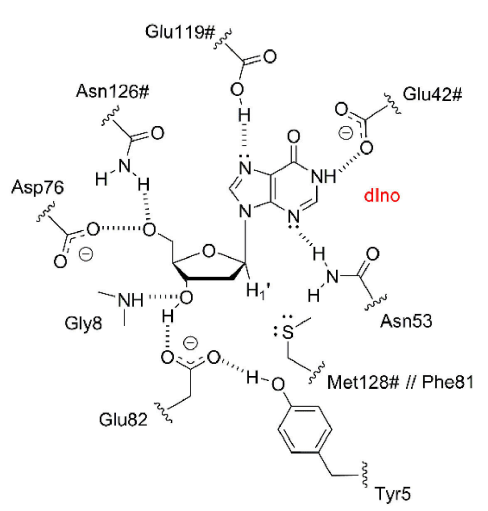

B

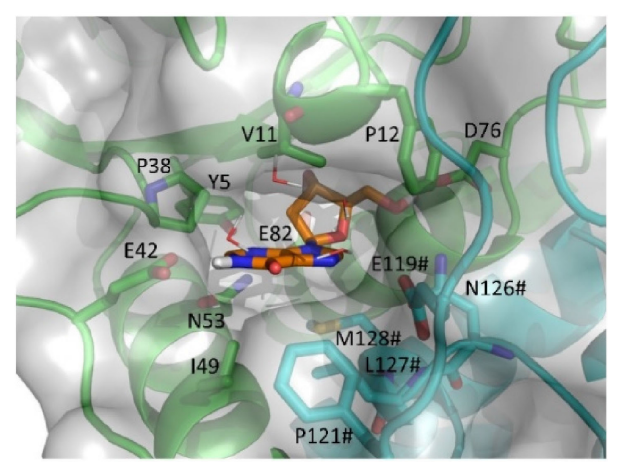

Figure 4. A. Schematic drawing of the binding of 2'-deoxyinosine (dlno) within the active site of TbPDT. B. Detail of a 3D model of the TbPDT active site (C atoms colored in green in one monomer and in cyan in the other) with a bound dlno molecule ( $\mathrm{C}$ atoms in orange) in the near-attack conformation. ${ }^{[14]}$ Enzyme residues making up the active site and relevant for catalysis are labeled and shown as sticks. 


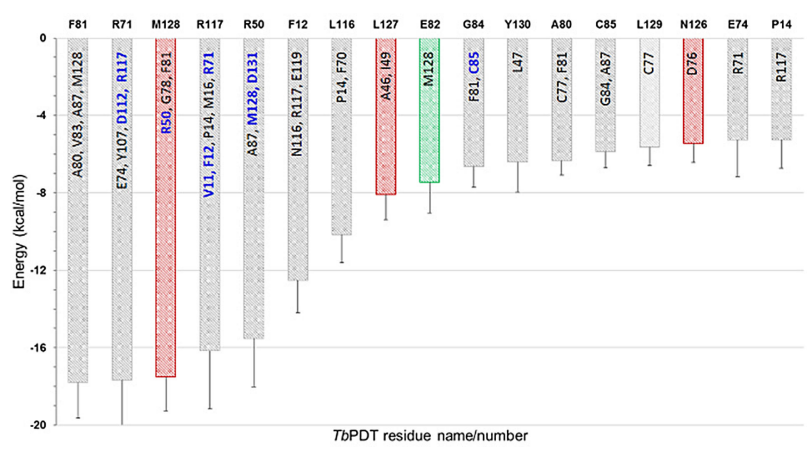

Figure 5. Binding energy analysis of the TbPDT dimer interface. The bars corresponding to residues from the NLM motif are colored in red whereas that belonging to the catalytic Glu residue is colored in green. Those residues involved in inter-subunit hydrogen bonding interactions are labeled in blue. For simplicity, a cutoff of $5 \mathrm{kcal} \mathrm{mol}^{-1}$ was used.

region which is thought to largely determine the dimeric, tetrameric or hexameric functional state of NTDs. ${ }^{[9]}$

In addition to these non-bonded interactions, we note that Cys77 and Cys77\# are spatially close enough to be involved in a disulfide bridge, despite the lack of electron density between the sulfur atoms in publicly available X-ray crystal structures of both TbPDT and LmPDT (PDB entries $2 \mathrm{AOK} \mathrm{K}^{[10]}$ and $5 \mathrm{NBR}^{[9]}$ respectively). This is most likely due to the fact that these highly homologous proteins were expressed in the cytoplasm of $E$. coli cells, where the thioredoxin/thioredoxin reductase and glutathione/glutaredoxin pathways provide a reducing environment that prevents Cys oxidation. ${ }^{[20]}$ It is conceivable that, in an oxidizing environment, this intersubunit disulfide would further contribute to dimer stabilization.

\section{Enzymatic Synthesis of Non-Natural Nucleosides}

To explore the potential of TbPDT as a biocatalyst, the enzymatic synthesis of several nucleoside analogues was carried out. A variety of natural and non-natural nucleosides and bases were employed under different assay conditions. To determine whether TbPDT can synthesize nucleoside analogues from natural nucleosides and purine base analogues, the best nucleoside substrate, dlno (Table 1), was selected as the base donor. As shown in Table 2, TbPDT catalyzes most of the transfer reactions assayed with moderately good conversion rates at short reaction times. In this regard, the syntheses of therapeutic nucleosides such as 2-FdAdo (5, a prodrug used in suicide gene therapy for cancer treatment $)^{[21]}$ and cladribine (4, an FDAapproved drug for the treatment of hairy-cell leukemia), ${ }^{[22]}$ or 6MPdRib (6, a precursor of 6-MP, a Hyp analogue used in the treatment of childhood acute lymphocytic leukemia) ${ }^{[22]}$ were undertaken as test cases.

Over the last decades, C2'- and/or C3'-modified nucleosides have received a great deal of attention in connection with the quest for new antineoplastic drugs and antiviral agents (particularly against HIV). ${ }^{[1,21]}$ Prominent among them are vidarabine (7), fludarabine (8), nelarabine (9), ddl (10), zidovudine (3'-azido-2', $3^{\prime}$-dideoxythymidine, AZT), zalcitabine $\left(2^{\prime}, 3^{\prime}\right.$ -

\begin{tabular}{|cccc|}
\hline \multicolumn{2}{|c|}{ Table 2. Synthesis of nucleoside analogues from purine base derivatives } \\
catalyzed by TbPDT.
\end{tabular}

[a] Reaction conditions: $0.3 \mu \mathrm{g}$ of enzyme in $40 \mu \mathrm{L}$ at $50^{\circ} \mathrm{C}, 20 \mathrm{~min}$. [Substrates] $=1 \mathrm{mM}, 50 \mathrm{mM}$ sodium phosphate buffer, pH 6.0. n.d. not detected

dideoxycytidine, ddC), stavudine $\left(2^{\prime}, 3^{\prime}\right.$-didehydro- $2^{\prime}, 3^{\prime}$-dideoxythymidine, d4T), lamivudine $\left(2^{\prime}, 3^{\prime}\right.$-dideoxy-3'-thiacytidine, emtricitabine ( $2^{\prime}, 3^{\prime}$-dideoxy-5-fluoro-3'-thiacytidine), and other sugarmodified nucleosides of natural bases. ${ }^{[1,21]}$

Given the relative tolerance of TbPDT to various modifications at positions $\mathrm{C2}^{\prime}$ and $\mathrm{C}^{\prime}$ of the deoxyribose moiety, we tested its ability to act as a transglycosylation biocatalyst for the synthesis of 2'-fluoro-2'-deoxyribosyl, 2',3'-dideoxy-ribosyl and arabinosyl nucleosides containing natural purines (Table 3). To illustrate the therapeutic importance of these molecules, suffice it to say that ddG is a selective inhibitor of HIV replication in vitro and an active anti-hepadnavirus nucleoside analogue ${ }^{[23]} \mathrm{ddl}(10)$ is a potent inhibitor of HIV replication, ${ }^{[24]}$ vidarabine (7) is not only an antiviral drug active against herpes simplex and varicella zoster viruses but also a potential precursor of fludarabine and clofarabine, both FDA-approved drugs for cancer treatment, ${ }^{[1 a, 25]}$ and $2^{\prime} \mathrm{F}-\mathrm{dGuo}$ is an antiinfluenza virus agent. ${ }^{[26]}$

Likewise, the considerable latitude of TbPDT in nucleobase recognition was advantageously used to produce a further set of 2',3'-modified nucleoside analogues containing substituted purines, such as 2-FAde, 2-ClAde, 2,6-DAP, 6-CIPur, 6-MP, 6MetPur, 6-MeGua (Table 3). As therapeutically relevant examples, we highlight nelarabine (9), an ara G prodrug, and fludarabine (8), both of which are FDA-approved chemotherapeutic agents for the treatment of several malignancies. ${ }^{[2]}$

Noteworthy, these results demonstrate, for the first time to the best of our knowledge, that an NDT can successfully synthesize ara 2-FAde, ara 2-CIAde, ara 6-CIPur, ara 6-MeOGua, dd2,6-DAPRib, dd6MRib, dd2-FAdo, dd2-ClAdo, dd6-ClPurRib, dd6-MeOdGuo, 2'F-2,6-DAPdRib, 2'F-6-MdRib, 2'F-2-FdAdo, 2'F2-CldAdo, 2'F-6-CIPurdRib, and 2'F-6-MeOdGuo.

\section{Site-Directed Mutagenesis and Kinetic Characterization of the Wild-Type TbPDT and Engineered Variants}

Our MD simulations suggested that Val11, a non-catalytic residue that is positionally close to the interfacial Phe12, provides a hydrophobic environment for binding of the heterocyclic ring system of both the nucleoside donor and the acceptor base. In doing so the bulky side chain of Val11 plays a 


\begin{tabular}{|c|c|c|c|}
\hline Donor & Acceptor & Product & Conversion [\%] \\
\hline \multirow[t]{9}{*}{$d d A$} & Gua & ddG & $24 \pm 3$ \\
\hline & Hyp & ddl & $27 \pm 1$ \\
\hline & 2-FAde & dd2-FAdo & $16 \pm 2$ \\
\hline & 2-ClAde & dd2-CIAdo & n.d. \\
\hline & 2,6-DAP & dd2,6-DAPRib & $16 \pm 2$ \\
\hline & 6-CIPur & dd6-CIPurRib & $10 \pm 3$ \\
\hline & 6-MP & dd6-MPRib & 2 \\
\hline & 6-MetPur & dd6-MetPurRib & $6 \pm 1$ \\
\hline & 6-MeOGua & dd6-MeOGuo & $18 \pm 1$ \\
\hline \multirow[t]{9}{*}{ ddl } & Ade & $\mathrm{dd} A$ & $17 \pm 1$ \\
\hline & Gua & ddG & 20 \\
\hline & 2-FAde & dd2-F-dAdo & - \\
\hline & 2-ClAde & dd2-CldAdo & n.d. \\
\hline & 2,6-DAP & dd2,6-DAPRib & 10 \\
\hline & 6-CIPur & dd6-CIPurRib & 6 \\
\hline & 6-MP & dd6-MPRib & 2 \\
\hline & 6-MetPur & dd6-MetPurRib & 4 \\
\hline & 6-MeOGua & dd6-MeOGuo & 7 \\
\hline \multirow[t]{9}{*}{$\operatorname{ara} \mathrm{A}$} & Gua & ara G & $43 \pm 1$ \\
\hline & Hyp & ara $\mathrm{H}$ & $55 \pm 1$ \\
\hline & 2-FAde & ara 2-FAdo & 23 \\
\hline & 2-ClAde & ara 2-CIAdo & 13 \\
\hline & 2,6-DAP & ara 2,6-DAP & 29 \\
\hline & 6-CIPur & ara 6-CIPur & 7 \\
\hline & 6-MP & ara 6-MP & n.d. \\
\hline & 6-MetPur & ara 6-MetPur & 15 \\
\hline & 6-MeOGua & ara 6-MeOGuo & $38 \pm 1$ \\
\hline \multirow[t]{9}{*}{ ara G } & Ade & ara $\mathrm{A}$ & $37 \pm 1$ \\
\hline & Hyp & ara $\mathrm{H}$ & $50 \pm 1$ \\
\hline & 2-FAde & ara 2-FAdo & 37 \\
\hline & 2-ClAde & ara 2-ClAdo & $17 \pm 1$ \\
\hline & 2,6-DAP & ara 2,6-DAP & 28 \\
\hline & 6-CIPur & ara 6-CIPur & 8 \\
\hline & 6-MP & ara 6-MP & 21 \\
\hline & 6-MetPur & ara 6-MetPur & 14 \\
\hline & 6-MeOGua & ara 6-MeOGuo & 52 \\
\hline \multirow[t]{9}{*}{ 2'F-dlno } & Ade & 2'F-dAdo & 29 \\
\hline & Gua & 2'F-dGuo & 36 \\
\hline & 2-FAde & 2'F-2-F-dAdo & 21 \\
\hline & 2-ClAde & 2'F-2-CldAdo & 15 \\
\hline & 2,6-DAP & 2'F-2,6-DAPdRib & 15 \\
\hline & 6-CIPur & 2'F-6-CIPurdRib & 4 \\
\hline & 6-MP & 2'F-6-MPdRib & $10 \pm 1$ \\
\hline & 6-MetPur & 2'F-6-MetPurdRib & 4 \\
\hline & 6-MeOGua & 2'F-6-MeOdGuo & 15 \\
\hline \multicolumn{4}{|c|}{$\begin{array}{l}\text { [a] Reaction conditions were } 8 \mu \mathrm{g} \text { of enzyme in } 40 \mu \mathrm{L} \text { at } 50^{\circ} \mathrm{C} \text { for } 4 \mathrm{~h} \text {. } \\
\text { Substrate concentration was } 1 \mathrm{mM} \text { in } 50 \mathrm{mM} \text { sodium phosphate buffer, } \\
\text { pH 6.0, except for Gua, in which case it was } 10 \mathrm{mM} \text { in } 50 \mathrm{mM} \text { sodium } \\
\text { borate buffer, pH 8.5. n.d. not detected. }\end{array}$} \\
\hline
\end{tabular}

\begin{tabular}{|lcc|}
\hline $\begin{array}{l}\text { Table 4. Enzymatic activities } \\
\text { transglycosylation reactions. }{ }^{\text {[a] }}\end{array}$ & $\begin{array}{c}\text { Specific activity [IU/mg protein] } \\
\text { dlno + Ade }\end{array}$ & dGuo + Ade \\
\hline Wild type & $38.5 \pm 4.2$ & $21.4 \pm 3$ \\
V11A & $84.7 \pm 2$ & $50.3 \pm 2$ \\
V11S & $90.7 \pm 3$ & $59.9 \pm 2$ \\
\hline [a] Reaction conditions: $0.3 \mu$ of enzyme in $40 \mu \mathrm{L}$ at $50^{\circ} \mathrm{C}, 5 \mathrm{~min}$. \\
[Substrates] $=10 \mathrm{mM}, 50 \mathrm{mM}$ sodium phosphate buffer, $\mathrm{pH} 6.0$. \\
\hline
\end{tabular}

dual role; on the one hand, by stacking on the heterobase, it contributes to the binding energy; on the other hand, its apolar character prevents the approach of incoming water molecules that might be activated for attack on the deoxyribosyl-enzyme intermediate to release the bonded sugar.

To assess this dual role, two variants $\left(T_{b P D T} \mathrm{~V} 11 \mathrm{~A}_{\mathrm{A}}\right.$ and $T_{b P D T} T_{\text {1115 }}$ ) were generated by single amino acid substitutions at position 11 and their transferase activities were determined using Ade as the acceptor base and either dlno or dGuo as the nucleoside donor. The specific activity of each of these two variants was $>2$-fold that of the wild-type enzyme (Table 4). To gain further insight into the factor (s) responsible for these differences, steady-state kinetic studies were performed. Our results show that the rates of catalysis for the two halfreactions, i.e. nucleobase release and transglycosylation, are enhanced in both variants, despite the higher $K_{M}$ values, which probably reflect the expected loss in van der Waals and hydrophobic interactions between enzyme and substrates (Table 5). Since enhanced transition state stabilization associated to increased flexibility of the active site is the single factor thought to be a requirement for reducing the free energy barrier and accelerate the enzymatic reaction, ${ }^{[27]}$ this must be the overall effect of replacing Val11 with the less bulky Ala or Ser residues. Nonetheless, further experimental and theoretical work will be necessary to ascertain the origin of the improved catalytic efficiencies of these variants.

Immobilization of recombinant TbPDT onto glutaraldehyde-activated MagReSyn ${ }^{\circledR}$ Amine microspheres Since immobilization is an essential requirement for the use of enzymes as industrial biocatalysts, we assayed the stability of TbPDT under immobilization conditions. Covalent immobilization of proteins is usually achieved via multipoint covalent attachment through

\begin{tabular}{|c|c|c|c|c|c|c|}
\hline Parameter & Wild type & Variable dlno & V11S & Wild type & $\begin{array}{l}\text { V11A } \\
\text { Variable }\end{array}$ & V11S \\
\hline \multicolumn{7}{|c|}{ Nucleobase release } \\
\hline$K_{M}[\mathrm{mM}]$ & $0.7 \pm 0.2$ & $5.1 \pm 1.1$ & $6.8 \pm 1.6$ & $0.6 \pm 0.2$ & $2.7 \pm 0.9$ & $1.4 \pm 0.4$ \\
\hline$k_{\text {cat }}\left[\mathrm{s}^{-1}\right]$ & $7.9 \pm 1.3$ & $39.6 \pm 4.0$ & $40.7 \pm 3.9$ & $8.7 \pm 0.95$ & $21.5 \pm 1.6$ & $19.6 \pm 1.9$ \\
\hline$k_{\text {cat }} / K_{M}\left[\mathrm{~s}^{-1} \mathrm{M}^{-1}\right]$ & 11314 & 7765 & 5985 & 14500 & 7962 & 14000 \\
\hline $\begin{array}{l}V_{\max } \\
\text { Transglycosylati }\end{array}$ & $0.21 \pm 0.01$ & $1.05 \pm 0.06$ & $1.08 \pm 0.09$ & $0.23 \pm 0.04$ & $0.57 \pm 0.10$ & $0.52 \pm 0.09$ \\
\hline$K_{M}[\mathrm{mM}]$ & $0.2 \pm 0.1$ & $1.2 \pm 0.4$ & $2.0 \pm 0.9$ & $1.8 \pm 0.2$ & $2.9 \pm 0.7$ & $2.9 \pm 0.6$ \\
\hline$k_{\text {cat }}\left[\mathrm{s}^{-1}\right]$ & $6.4 \pm 1.3$ & $14.3 \pm 3.4$ & $17.0 \pm 2.6$ & $10.2 \pm 1.1$ & $23.4 \pm 2.3$ & $23.8 \pm 2.9$ \\
\hline$k_{\text {cat }} / K_{M}\left[\mathrm{~s}^{-1} \mathrm{M}^{-1}\right]$ & 30476 & 11440 & 8415 & 5600 & 8068 & 8206 \\
\hline $\mathrm{V}_{\max }$ & $0.17 \pm 0.01$ & $0.38 \pm 0.03$ & $0.45 \pm 0.06$ & $0.27 \pm 0.04$ & $0.62 \pm 0.04$ & $0.63 \pm 0.05$ \\
\hline
\end{tabular}


the region with the highest density of primary amino groups, especially the $\varepsilon-\mathrm{NH}_{2}$ of lysine residues. ${ }^{[28]}$ These covalent immobilization techniques usually employ long reaction times (4-10 h) and alkaline conditions ( $\mathrm{pH} \mathrm{8-10).} \mathrm{For} \mathrm{this} \mathrm{reason,} \mathrm{we}$ thought that the exceptional stability displayed by TbPDT under alkaline conditions could offer a substantial advantage for efficient immobilization on magnetic particles. TbPDT immobilization was carried out by covalent attachment of the enzyme to glutaraldehyde-activated MagReSyn ${ }^{\circledR}$ Amine microspheres (Scheme 1).

Different immobilized biocatalysts (MTbPDT1-MTbPDT5) were prepared by increasing the enzyme load and MTbPDT3 was selected as the optimum construct (Table 6) because it showed a remarkably high activity of $4200 \mathrm{IU} / \mathrm{g}$ of wet biocatalyst (in the synthesis of dAdo from dlno and adenine at $50^{\circ} \mathrm{C}$ and $50 \mathrm{mM}$ sodium phosphate $\mathrm{pH} 6$ ) and an activity recovery ${ }^{[29]}$ of $\sim 22 \%$. Noteworthy, MTbPDT3 displays the highest activity ever described for an immobilized NDT. The calculated specific activities for MTbPDT3 are much higher (between 64.2 and 1615 times) than those reported for other NDTs, such as that from LrNDT immobilized on epoxy-activated Sepabeds ${ }^{\circledR}$ for the enzymatic synthesis of dAdo $(65.4 \mathrm{lU} / \mathrm{g}$ of wet biocatalyst ${ }^{[30]}$ or that from Bacillus psychrosaccharolyticus (BpNDT) immobilized on PEI $600 \mathrm{Da}$ agarose followed by crosslinking with $70 \%$ oxidized dextran $(20 \mathrm{kDa})(11.3 \mathrm{lU} / \mathrm{g}$ of wet biocatalyst). ${ }^{[31]}$ Other similar examples, such as the enzymatic synthesis of thymidine by LrNDT immobilized on magnetic chitosan beads $(2.10 \mathrm{lU} / \mathrm{g} \text { of wet biocatalyst })^{[7]}$ or the enzymatic synthesis of halogenated nucleosides by an NDT from Lactobacillus animalis (LaNDT) immobilized on DEAESepharose (2.6-5.4 IU/g of wet biocatalyst) ${ }^{[32]}$ displayed very low activity values compared to MTbPDT3.
In addition, MTbPDT3 could be recycled after at least 25 consecutive batch reactions with negligible loss of catalytic activity in the synthesis of dAdo from dino and Ade.

A physical characterization of magnetic particles can be of help to establish the optimal conditions in the bioreactor. SEM micrographs of MTbPDT3 (Figure S3) showed individual particles in a micro-size scale and with a rough surface. This irregular surface might enhance enzyme attachment and expand the number of internal spaces available for substrate binding. Thus, this carrier material might be close to ideal due to its high accessible surface area and the nanoscaled intrapore system that allows both stable enzyme binding and high flow permeability. ${ }^{[33]}$ Furthermore, DLS analysis of these systems revealed a Z-average size between 24.6-113.42 $\mu \mathrm{m}$ and 4.96$19.50 \mu \mathrm{m}$ for the free MagReSyn ${ }^{\circledR}$ Amine beads and MTbPDT3, respectively. As Manoel et al. demonstrated with poly (styreneco-divinylbenzene)-based supports, ${ }^{[34]}$ this micrometric size is normally desirable to enable the industrial implementation of biocatalysts because it avoids the use of complex methods for separation of the biocatalyst from the reaction media and the diffusional problems associated to very small or very large particles, respectively. These results reveal that the enzyme displayed on the surface of magnetic devices can reduce the presence of aggregates in water dispersion and, therefore, promote the stability of individual particles. This explanation is in accordance with zeta potential measurements.

Thus, the zeta potentials of free MagReSyn ${ }^{\circledR}$ Amine beads were between -0.5 and $-0.8 \mathrm{mV}$ and decreased to -64.1 and $-67.6 \mathrm{mV}$ upon enzyme immobilization due to surface charge modification. The measurement conditions and the immobilized enzyme seem to reduce the flocculating behavior of free MagReSyn ${ }^{\circledR}$ Amine beads. The zeta potential is used mainly as an indicator of electrostatic stabilization of colloidal particles, in agreement with the DLVO theory, ${ }^{[35]}$ according to which large

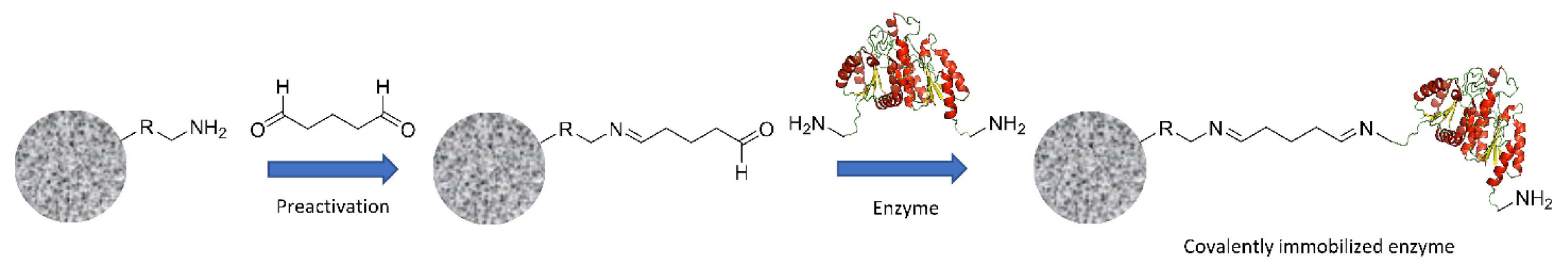

Scheme 1. Schematic representation of immobilization of recombinant TbPDT on glutaraldehyde-activated MagReSyn ${ }^{\circledR}$ Amine microspheres.

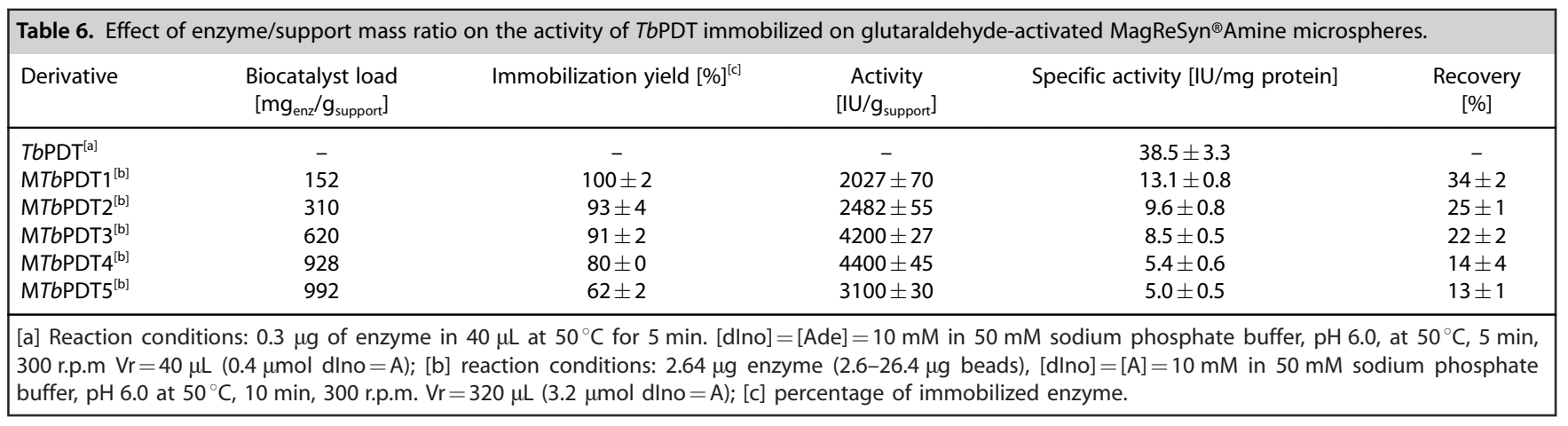


magnitude zeta potential values, such as those measured for the MTbPDT3 beads, indicate that an electrostatically stabilized suspension will remain stable, unlike free MagReSyn ${ }^{\circledR} \mathrm{Amine}$ beads, which have a zeta potential close to zero.

Finally, as a proof of concept, MTbPDT3 was successfully employed in the one-pot, one-step synthesis of several nucleoside analogues of pharmaceutical interest using dGuo as the nucleoside donor with conversion rates approaching $50 \%$ (Table 7).

\begin{tabular}{|lcccc|}
\hline \multicolumn{3}{|l}{ Table 7. MTbPDT3-catalyzed synthesis of nucleoside analogues. ${ }^{\text {[a] }}$} \\
Donor & Acceptor & Product & $\begin{array}{c}\text { Activity } \\
{\left[\text { [U/g }_{\text {support }} \text { ] }\right.}\end{array}$ & $\begin{array}{c}\text { Nucleoside } \\
\text { conversion [\%] }\end{array}$ \\
\hline dGuo & 2-FAde & 2-FdAdo & $3424 \pm 30$ & $40 \pm 2$ \\
& 2-ClAde & 2-CldAdo & $3521 \pm 35$ & $41 \pm 2$ \\
& 2,6-DAP & 2,6-DAPdRib & $3057 \pm 50$ & $33 \pm 5$ \\
6-MeOGua & 6-MeOdGuo & $5101 \pm 75$ & $46 \pm 3$ \\
\hline
\end{tabular}

[a] Reaction conditions: $2.64 \mu \mathrm{g}$ prot $(4.25 \mu \mathrm{g}$ beads), [dGuo] $=$ [Base] $=$ $1 \mathrm{mM}$ in $50 \mathrm{mM}$ sodium phosphate buffer, $\mathrm{pH} 6.0$ at $50^{\circ} \mathrm{C}, 20 \mathrm{~min}, 300$ r.p.m. $\mathrm{Vr}=320 \mu \mathrm{L}(3.2 \mu \mathrm{mol}$ dlno=Base).

\section{Conclusions}

The presence of NDTs in Trypanosoma species has not been ascertained yet, despite a report ${ }^{[10]}$ on the crystal structure of a protein annotated in bioinformatic databases as a putative NDT from Trypanosoma brucei, the function of which has not been described, to the best of our knowledge. We now report the cloning of the pdt gene, its expression in E. coli, and the purification and biochemical characterization of the encoded protein, TbPDT. Our experimental results reveal TbPDT as a homodimeric enzyme endowed with significant activity in a broad range of temperature $\left(50-70^{\circ} \mathrm{C}\right), \mathrm{pH}(4-7)$ and ionic strength $(0-500 \mathrm{mM})$ values. Additionally, TbPDT was found to exhibit great stability in a pH interval from 6.5 to 10.0 and display negligible loss of activity at $50^{\circ} \mathrm{C}$ for $30 \mathrm{~h}$. The potential of TbPDT for biocatalysis was demonstrated by achieving the enzymatic synthesis of numerous therapeutic nucleosides, including 2-CIAdo (4), vidarabine (7), fludarabine (8), nelarabine (9), and ddl (10), among others (Tables 2 and 3).

The covalent immobilization of TbPDT on glutaraldehydeactivated MagReSyn ${ }^{\circledR}$ Amine microspheres led to derivative MTbPDT3, which displayed a remarkable activity of $4200 \mathrm{lU} / \mathrm{g}$ of wet biocatalyst and retained $22 \%$ activity in the enzymatic synthesis of dAdo from dlno and adenine. Furthermore, MTbPDT3 was reutilized for at least 25 times without any apparent loss of catalytic activity, an essential prerequisite for its application in industrial bioreactors, and allowed the expedient enzymatic synthesis of several nucleoside analogues at moderate conversion rates.

\section{Experimental Section}

\section{Materials}

Cell culture medium reagents were from Difco (St. Louis, United States). Trimethyl ammonium acetate buffer was purchased from Sigma-Aldrich (Madrid, Spain). All other reagents and organic solvents were purchased from Scharlab (Barcelona, Spain) and Symta (Madrid, Spain). Nucleosides and nucleobases used in this work were provided by Carbosynth Ltd. (Compton, United Kingdom).

\section{Gene Expression and Protein Purification}

The $p d t$ gene, which encodes a protein annotated as nucleoside 2 deoxyribosyltransferase from Trypanosoma brucei gambiense (European Nucleotide Archive code: AAX70453.1; UniProtKB Q57VC7, was purchased from Genscript (USA). The coding sequence appeared as a Ndel-Ecorl fragment subcloned into the expression vector $\mathrm{pET} 28 \mathrm{~b}(+)$. The resultant, recombinant vector $\mathrm{pET} 28 \mathrm{~b} T b \mathrm{bDT}$ provided an $\mathrm{N}$-terminal His6-tagged fusion with a thrombin cleavage site between the tag and the enzyme. TbPDT was expressed in E. coli BL21 (DE3) grown in LB medium at $37^{\circ} \mathrm{C}$ with kanamycin $50 \mu \mathrm{g} / \mathrm{mL}$. Protein overexpression was induced by adding $0.5 \mathrm{mM}$ isopropyl $\beta$-D-1-thiogalactopyranoside and the cells were further grown for $3 \mathrm{~h}$. These were harvested via centrifugation at $3500 \times g$. The resulting pellet was resuspended in $10 \mathrm{mM}$ sodium phosphate buffer $\mathrm{pH}$ 7. Crude extracts were prepared by French press lysis of cell suspensions. The lysate was centrifuged at $17500 \times g$ for $30 \mathrm{~min}$ and the supernatant was filtered through a $0.22 \mu \mathrm{m}$ filter (Millipore). The cleared lysate was loaded onto a $5-\mathrm{mL}$ HisTrap FF column (GE Healthcare) pre-equilibrated in a binding buffer $(20 \mathrm{mM}$ Tris- $\mathrm{HCl}$ buffer, $\mathrm{pH} 8.0$, with $100 \mathrm{mM} \mathrm{NaCl}$ and $10 \mathrm{mM}$ imidazole) and the column was washed. Bound proteins were eluted using a linear gradient of imidazole (from 10 to $500 \mathrm{mM}$ ). Fractions containing TbPDT were identified by SDS-PAGE, pooled, concentrated and loaded onto a HiLoad 16/60 Superdex 200 prep grade column (GE Healthcare) pre-equilibrated in $50 \mathrm{mM}$ sodium phosphate, $\mathrm{pH}$ 7.0. Fractions with the protein of interest identified by SDS-PAGE were pooled and the protein was dialyzed against $10 \mathrm{mM}$ sodium phosphate, $\mathrm{pH} 7.0$, and concentrated and stored at $4^{\circ} \mathrm{C}$ until its use. Electrophoresis was carried out on a $15 \%$ polyacrylamide slab gel with $25 \mathrm{mM}$ Tris- $\mathrm{HCl}$ buffer, $\mathrm{pH} 8.6$, $0.1 \%$ SDS. ${ }^{[36]}$ Protein concentration was determined spectrophotometrically by UV absorption at $280 \mathrm{~nm}$ using $\varepsilon_{280}=$ $8,940 \mathrm{M}^{-1} \mathrm{~cm}^{-1} \cdot[37]$

\section{Analytical Ultracentrifugation Analysis}

Sedimentation velocity experiments for TbNDT were carried out in $10 \mathrm{mM}$ sodium phosphate $\left(\mathrm{pH} 8.0,20^{\circ} \mathrm{C}, 50,000 \times \mathrm{g}\right)$ using an Optima XL-I analytical ultracentrifuge (Beckman-Coulter Inc.) equipped with UV-VIS absorbance and Raleigh interference detection systems, using an An-60Ti rotor and standard $(12 \mathrm{~mm}$ optical path) double-sector centre pieces of Epon-charcoal. Sedimentation profiles were recorded at $292 \mathrm{~nm}$. Sedimentation coefficient distributions were calculated by least-squares boundary modeling of sedimentation velocity using the continuous distribution $c(s)$ Lamm equation model as implemented in SEDFIT $14.7 \mathrm{~g} .^{[38]}$ (https://sedfitsedphat.nibib.nih.gov/software/default.aspx). Baseline off-sets were measured afterwards at 200,000 $\times g$. The experimental sedimentation coefficients were corrected to standard conditions (water, $20^{\circ} \mathrm{C}$, and infinite dilution) using SEDNTERP software to obtain the corresponding standard values $\left(s_{20, w}\right) .^{[39]}$ 


\section{Enzyme Activity Assay}

The standard activity assay was performed by incubating $0.3 \mu \mathrm{g}$ of pure enzyme with $10 \mathrm{mM} 2$-deoxyinosine (dlno) and $10 \mathrm{mM}$ adenine in $50 \mathrm{mM}$ sodium phosphate buffer $\mathrm{pH} 6.5$ in a final volume of $40 \mu \mathrm{L}$. The reaction mixture was incubated at $40^{\circ} \mathrm{C}$ for $10 \mathrm{~min}(300 \mathrm{rpm})$. The enzyme was inactivated by adding $40 \mu \mathrm{L}$ of cold methanol in an ice bath and heating for $5 \mathrm{~min}$ at $100^{\circ} \mathrm{C}$. After centrifugation at $9000 \times g$ for $2 \mathrm{~min}$, the samples were half-diluted with water and frozen at $-20^{\circ} \mathrm{C}$. Nucleoside production was analyzed using HPLC to measure the reaction products quantitatively, as described below. All determinations were carried out in triplicate and the maximum error was less than $5 \%$. Under such conditions, one international activity unit (IU) was defined as the amount of enzyme producing $1 \mu \mathrm{mol} / \mathrm{min}$ of 2'-deoxyadenosine under the assay conditions.

\section{Influence of pH and Temperature on Enzyme Activity}

The $\mathrm{pH}$ profile of purified recombinant enzyme was initially determined using the standard assay, as described above, with sodium citrate $(\mathrm{pH} 4-6)$, sodium phosphate $(\mathrm{pH} \mathrm{6-8)}$ and sodium borate $(\mathrm{pH} 8-10)$ as reaction buffers $(50 \mathrm{mM})$. The optimum temperature was determined using the standard assay across a 20$90^{\circ} \mathrm{C}$ range. A similar approach was followed to characterize the effect of ionic strength on enzyme activity. TbPDT activity was measured at different concentrations of $\mathrm{NaCl}$, ranging from 0 to $1 \mathrm{M}$.

\section{Thermal and pH Stability of TbNDT}

TbPDT was stored at $4{ }^{\circ} \mathrm{C}$ in $10 \mathrm{mM}$ sodium phosphate, $\mathrm{pH} 7.0$ for 135 days. Samples were taken periodically for enzymatic activity evaluation. Storage stability was defined as the relative activity between the first and successive reactions. Moreover, the thermal stability of TbNDT was assessed by incubating $0.3 \mu \mathrm{g}$ of pure enzyme in a pH range from 6.5 to 10 , at $50^{\circ} \mathrm{C}$ for a period of $30 \mathrm{~h}$. Thereafter, the activity was measured using the standard assay.

\section{Substrate Specificity}

To explore the substrate specificity of TbPDT, $0.3 \mu \mathrm{g}$ of recombinant enzyme were incubated with $10 \mathrm{mM}$ of purine and pyrimidine nucleosides and bases, in $50 \mathrm{mM}$ sodium phosphate buffer $\mathrm{pH} 6.0$ or $50 \mathrm{mM}$ sodium borate $\mathrm{pH} 8.5$ at $50^{\circ} \mathrm{C}$ and $300 \mathrm{rpm}$ orbital shaking at different reaction times. Samples were extracted at regular intervals and enzymatic activity was evaluated as described in the Analytical methods section.

\section{Enzymatic Synthesis of Nucleoside Analogues by Soluble TbPDT.}

The synthesis of non-natural nucleosides was achieved at variable amounts of enzyme, using different nucleoside and base analogues. Reactions were carried out incubating $0.3-8 \mu \mathrm{g}$ of TbPDT with $1 \mathrm{mM}$ nucleoside and base, in $50 \mathrm{mM}$ sodium phosphate buffer $\mathrm{pH} 6.0$ or sodium borate $\mathrm{pH} 8.5$ at $50^{\circ} \mathrm{C}$ and $300 \mathrm{rpm}$ orbital shaking at different reaction times. Samples were taken at regular intervals and enzymatic activity was evaluated as described below.

\section{Kinetic Parameters and Initial Velocity Pattern}

The steady-state kinetic parameters, $K_{M}, k_{\text {cat }}$ and $V_{\max }$ were determined under standard assay conditions at varying concen- trations of one substrate (dlno or Ade, $0.25-15 \mathrm{Mm}$ ), while the concentration of the other substrate was fixed at constant saturating level (dlno or Ade, $5 \mathrm{mM}$ ). Apparent $K_{M}, k_{\text {cat }}$ and $k_{\text {cat }} / K_{M}$ values were determined by non-linear regression assuming Michaelis-Menten kinetics.

\section{Enzyme Immobilization}

TbPDT immobilization was carried out by covalent attachment of the enzyme to glutaraldehyde-activated MagReSyn ${ }^{\circledR}$ Amine microspheres (from ReSyn Biosciences, Pretoria, South Africa) according to the recommendations of the manufacturer. $25 \mu \mathrm{L}$ of the bead suspension ( $20 \mathrm{mg} \mathrm{mL}^{-1}$ ) were washed and equilibrated in binding buffer (50 mM potassium phosphate buffer, $\mathrm{pH} 8.5$ ) during $4 \mathrm{~h}$ at $25^{\circ} \mathrm{C}$. After the equilibration procedure, the beads were collected by a magnetic separator and the supernatant was discarded. Activation of the support was accomplished by contacting MagReSyn ${ }^{\circledR}$ Amine microspheres with $200.0 \mu \mathrm{L}$ of $50 \mathrm{mM}$ sodium phosphate buffer $\mathrm{pH} 8.5$ containing $4 \%(\mathrm{w} / \mathrm{v})$ glutaraldehyde during $3 \mathrm{~h}$ at $25^{\circ} \mathrm{C}$, and then washed extensively with distilled water to remove the excess of the activating agent. Finally, activated microspheres were washed and equilibrated in binding buffer (50 mM potassium phosphate buffer, $\mathrm{pH} 8.5$ ) shortly prior to use.

Subsequently, different amounts of enzyme (25-125 $\mu \mathrm{g})$ were mixed with glutaraldehyde-activated MagReSyn ${ }^{\circledR}$ Amine microspheres. The enzyme solution with the binding buffer was adjusted to $10 \times$ the volume of the initial beads suspension. The enzyme and bead suspensions were mixed thoroughly and incubated at room temperature under orbital shaking using a Sunflower 3D MiniShaker (BioSan, Latvia) for $10 \mathrm{~h}$. After the binding procedure, the beads were collected by a magnetic separator and the supernatant was discarded. The beads were washed with washing buffer (50 $\mathrm{mM}$ potassium phosphate buffer, $\mathrm{pH} 8.5 ; 1 \mathrm{M} \mathrm{NaCl}$ ) for three times to remove non-covalently bound enzyme. After this, the beads were also treated with $1 \mathrm{M}$ Tris- $\mathrm{HCl}, \mathrm{pH} 9.0$ for $3 \mathrm{~h}$ at room temperature to quench any remaining amine reactive residues on the microparticles. The beads were washed with $50 \mathrm{mM}$ potassium phosphate buffer ( $\mathrm{pH} 8.5)$ for three times and then stored at $4{ }^{\circ} \mathrm{C}$.

\section{Enzyme Activity Assay for Immobilized TbPDT}

As performed with the soluble enzyme, the enzymatic synthesis of dAdo from dino and Ade was established as the standard transglycosidase reaction. The enzymatic activity of the immobilized enzyme was measured using 2.6-26.4 $\mathrm{gg}$ of different MTbPDT derivatives (each containing $2.64 \mu \mathrm{g}$ of immobilized TbPDT) which were added to a $320 \mu \mathrm{L}$ solution containing $10 \mathrm{mM}$ dlno and $10 \mathrm{mM}$ Ade in $50 \mathrm{mM}$ phosphate buffer, $\mathrm{pH}$ 6.0. The reaction mixture was incubated at $50^{\circ} \mathrm{C}$ for 10 min under magnetic stirring. The reaction was stopped by collecting the beads with a magnetic separator and the supernatant was treated following the general procedure described above. Enzymatic activity (IU/mg of enzyme) was evaluated as described above to measure specific activity of the biocatalyst (IU/g derivative).

\section{Enzymatic Synthesis of Nucleoside Analogues by Immobilized TbPDT}

Non-natural nucleosides were synthesized by adding $4.25 \mu \mathrm{g}$ of MTbPDT3 (containing $2.64 \mu \mathrm{g}$ of immobilized TbPDT) to a $320 \mu \mathrm{L}$ solution containing $1 \mathrm{mM}$ dGuo and $1 \mathrm{mM}$ purine base analogues in $50 \mathrm{mM}$ sodium phosphate buffer $\mathrm{pH} 6.0$ at $50^{\circ} \mathrm{C}$ for $20 \mathrm{~min}$, under magnetic shaking. Enzymatic activity (IU/mg of enzyme) was 
evaluated as described above to measure specific activity of the biocatalyst (IU/g derivative).

\section{Analytical Methods}

The production of nucleosides was quantitatively measured with an ACE EXCEL $5 \mu \mathrm{m}$ CN-ES $250 \times 4.6 \mathrm{~mm}$ equilibrated with $100 \%$ trimethyl ammonium acetate at a flow rate of $0.8 \mathrm{~mL} / \mathrm{min}$. Retention times for the reference natural and non-natural bases (hereafter abbreviated according to the recommendations of the IUPAC-IUB Commission on Biochemical Nomenclature) were as follows: adenine (Ade), $10.2 \mathrm{~min}$; guanine (Gua), $7.3 \mathrm{~min}$; hypoxanthine (Hyp), $7.5 \mathrm{~min}$; 2-fluoroadenine (2-FAde), $14.4 \mathrm{~min}$; 2-chloroadenine (2-ClAde), $17.3 \mathrm{~min}$; 2,6-diaminopurine (2,6-DAP), $11.1 \mathrm{~min}$; 6-chloropurine (6-CIPur), $16.7 \mathrm{~min}$; 6-mercaptopurine (6-MP), $10.5 \mathrm{~min}$; 6-methylpurine (6-MetPur), $13.8 \mathrm{~min}$; 6-methoxyguanine (6-MeOGua), $16.4 \mathrm{~min}$; benzimidazole (Bzm), $29.6 \mathrm{~min}$, and theophylline (Theo), $18.42 \mathrm{~min}$.

Retention times for the nucleosides (hereafter abbreviated according to the recommendations of the IUPAC-IUB Commission on Biochemical Nomenclature) were as follows: 2'-deoxyadenosine (dAdo), $15.50 \mathrm{~min}$; 2'-deoxyguanosine (dGuo), $11.6 \mathrm{~min}$; 2'-deoxyinosine (dlno), $12.0 \mathrm{~min}$; 2-fluoro-2'-deoxyadenosine (2-F-dAdo), $14.4 \mathrm{~min}, 2$-chloro-2'-deoxyadenosine (2-CldAdo), $23.2 \mathrm{~min}$; 2,6diaminopurine-2'-deoxyribose (2,6-DAPdRib), $16.04 \mathrm{~min}$; 6-chloropurine-2'-deoxyribose (6-CIPurdRib), $22.9 \mathrm{~min}$; 6-mercaptopurine-2' deoxyribose (6-MPdRib), $13.5 \mathrm{~min}$; 6-methylpurine-2'-deoxyribose (6-MetPurdRib), $17.7 \mathrm{~min}$; 6-methoxy-2'-deoxyguanosine (6-MeOdGuo), $21.8 \mathrm{~min}$; benzimidazole-2'-deoxyribose (BzmdRib), $33.5 \mathrm{~min}$; arabinosyl adenine (ara A), $15.00 \mathrm{~min}$; arabinosyl guanine (ara G), $11.4 \mathrm{~min}$; arabinosyl hypoxanthine (ara H), $11.6 \mathrm{~min}$; arabinosyl 2fluoroadenine (ara 2-FAde), $13.8 \mathrm{~min}$; arabinosyl chloroadenine (ara 2-ClAde), $22.6 \mathrm{~min}$; arabinosyl 2,6-diaminopurine (ara 2,6-DAP), $15.8 \mathrm{~min}$; arabinosyl 6-chloropurine (ara 6-CIPur), $22.1 \mathrm{~min}$; arabinosyl 6-mercaptopurine (ara 6-MP), $13.2 \mathrm{~min}$; arabinosyl 6-methoxyguanine (ara 6-MeOGua), $21.4 \mathrm{~min} ; 2^{\prime}, 3^{\prime}$-dideoxyadenosine (ddAdo), $19.7 \mathrm{~min}$; 2',3'-dideoxyguanosine (ddGuo), $16.4 \mathrm{~min} ; 2^{\prime}, 3^{\prime}$ dideoxyinosine (ddlno), $15.9 \mathrm{~min}$; 2-fluoro-2',3'-dideoxyadenosine (dd2-Fado), $18.3 \mathrm{~min}$; 2-chloro-2', $3^{\prime}$-dideoxyadenosine (dd2-Clado), $27 \mathrm{~min}$; 2,6-diaminopurine-2', $3^{\prime}$-dideoxyribose (dd2,6-DAPRib), $20.9 \mathrm{~min}$; 6-chloropurine-2', $3^{\prime}$-dideoxyribose (dd6-CIPurRib), $27 \mathrm{~min}$ 6-mercaptopurine-2',3'-dideoxyribose (dd6MPRib), $19.5 \mathrm{~min} ; 2^{\prime}, 3^{\prime}$ dideoxy-6-methoxyguanosine (dd6-MeOGuo), $25.4 \mathrm{~min}$. 2'-fluoro-2' deoxyadenosine (2'F-dAdo), $17.8 \mathrm{~min}$; 2'-fluoro-2'-deoxyguanosine (2'F-dGuo), $16.3 \mathrm{~min}$; 2'-fluoro-2'-deoxyinosine (2'F-dlno), $13.9 \mathrm{~min}$ $2^{\prime}$-fluoro-2-fluoroadenosine (2'F-2FdAdo), $17.4 \mathrm{~min} ; \quad 2^{\prime}$-fluoro-2chloroadenosine (2'F-2CldAdo), $33.9 \mathrm{~min}$; 2'-fluoro-2,6-diaminopurine-2'-deoxyribose (2'F-2,6-DAPdRib), $18 \mathrm{~min}$; 2'-fluoro-6-chloropurine-2'-deoxyribose (2'F-CIPurdRib), 26 min; 2'-fluoro-6-mercaptopurine-2'-deoxyribose (2'F-6-MPdRib), $19 \mathrm{~min}$; 2'-fluoro-6methoxyguanosine (2'F-MeOdGuo), $24.6 \mathrm{~min}$.

\section{Scanning Electron Microscopy}

The morphology and particle structure of MagReSyn ${ }^{\circledR}$ Amine and TbPDT-MagReSyn ${ }^{\circledR}$ Amine beads (MTbPDT beads) were evaluated by SEM. SEM images were collected using a JEOL JSM-6400F electron microscopy equipped with a field emission gun at $10.0 \mathrm{kV}$ (Centro de Microscopía Electrónica, UCM, Madrid). The magnetic devices were dispersed in distilled water at room temperature $\left(25^{\circ} \mathrm{C}\right)$, deposited onto a metal support and coated with an ultrathin layer of gold.

Particle size distribution and zeta potential were also analyzed by DLS (Nanopartica, Horiba SZ-100, Braga, Portugal) at $25^{\circ} \mathrm{C}$. For this purpose, homogeneous dispersions of MagReSyn ${ }^{\circledR}$ Amine beads and MTbPDT beads in distilled water were prepared inside two different types of disposable cells. Scattered light was collected at a $90^{\circ}$ angle for size determinations and data were processed by Nanotrac Flex software. All quantifications were performed in quintuplicate.

\section{Computational Methods}

The AMBER force field ${ }^{[40]}$ was used for energy refinement and molecular dynamics simulations ${ }^{[4]]}$ of an all-atom representation of PDB entry $2 \mathrm{AOK}^{[10]}$ (upon removal of the $\mathrm{N}$-terminal His tag) in explicit solvent, following a previously described protocol. ${ }^{[42]} \mathrm{An}$ ensemble of 10 representative low-energy snapshots of TbPDT in complex with 2'-deoxyinosine (docked as reported earlier for 2'deoxyadenosine in $(m P D T)^{[9]}$ was used to calculate the solventcorrected intersubunit energy, as well as its decomposition into van der Waals, coulombic, apolar, and desolvation contributions by means of our in-house tool MM-ISMSA. ${ }^{[18]}$ The non-electrostatic calculations involve a van der Waals term, as in molecular mechanics (MM), and the change in solvent-accessible surface area (SASA) of both subunits brought about by dimer formation. The former, which accounts for shape complementarity, is calculated with the standard AMBER 12-6 Lennard-Jones potential whereas the latter ("apolar" in the Table), representing the nonpolar part of the desolvation process, is assumed to be linearly related to a combination of the cavitation term and the van der Waals solutesolvent interactions. The solvent-screened coulombic interactions were estimated by means of an implicit solvent model (ISM) that makes use of a sigmoidal, distance-dependent dielectric function. ${ }^{[43]}$ The pattern of interchain hydrogen bonds present in the TbPDT dimer was calculated and visualized using the PHP-based web application HBplot (www.virtuadrug.com/ hbplot) ${ }^{[19]}$, which employs the HBplus algorithm. ${ }^{[44]}$

\section{Acknowledgements}

This work was supported by grants SAN151610 from the Santander Foundation and 2016/UEM08 from the European University of Madrid to JFL and SAF2015-64629-C2-2-R from the Spanish Ministerio de Economía y Competitividad to FG.

\section{Conflict of Interest Statement}

Dr. Justin Jordaan has an interest in ReSyn Biosciences. For the purpose of this study, he advised on immobilization strategy but did not directly participate in the experimentation and did not generate any data.

Keywords: Biocatalysis • nucleoside analogues · 2'-deoxyribosyltransferase • enzyme immobilization - molecular dynamics

[1] a) T. Robak, E. Lech-Maranda, A. Korycka, E. Robak, Curr. Med. Chem. 2006, 13, 3165-3189; b) M. J. Lapponi, C. W. Rivero, M. A. Zinni, C. N. Britos, J. A. Trelles, J. Mol. Catal. B 2016, 133, 218-233.

[2] J. Boryski, Curr. Org. Chem. 2008, 12, 309-325.

[3] a) J. Fernández-Lucas, Appl. Microbiol. Biotechnol. 2015, 99, 4615-4627; b) A. Fresco-Taboada, I. de la Mata, M. Arroyo, J. Fernández-Lucas, Appl. 
Microbiol. Biotechnol. 2013, 97, 3773-3785; c) E. Lewkowicz, A. Iribarren, Curr. Org. Chem. 2006, 10, 1197-1215; d) I. Mikhailopulo, Curr. Org. Chem. 2007, 11, 317-335.

[4] a) P. A. Kaminski, J. Biol. Chem. 2002, 277, 14400-14407; b) J. FernándezLucas, C. Acebal, J. V. Sinisterra, M. Arroyo, I. de la Mata, Appl. Environ. Microbiol. 2010, 76, 1462-1470.

[5] K. A. Lawrence, M. W. Jewett, P. A. Rosa, F. C. Gherardini, Mol. Microbiol. 2009, 72, 1517-1529.

[6] P. A. Kaminski, P. Dacher, L. Dugue, S. Pochet, J. Biol. Chem. 2008, 283, 20053-20059.

[7] J. Fernández-Lucas, R. Harris, I. Mata-Casar, A. Heras, I. de la Mata, M. Arroyo, J. Ind. Microbiol. Biotechnol. 2013, 40, 955-966.

[8] a) G. Bayramoglu, M. Yilmaz, M. Yakup Arica, Bioprocess Biosyst. Eng. 2010, 33, 439-448; b) X. Zhou, I. A. Mikhailopulo, M. N. Cruz Bournazou, P. Neubauer, J. Mol. Catal. B 2015, 115, 119-127; c) J. del Arco, S Martínez-Pascual, V. Clemente-Suárez, O. Corral, J. Jordaan, D. Hormigo, A. Perona, J. Fernández-Lucas, Catalysts 2018, 8, 184.

[9] N. Crespo, P. A. Sánchez-Murcia, F. Gago, J. Cejudo-Sánches, M. A. Galmes, J. Fernández-Lucas, J. M. Mancheño, Appl. Microbiol. Biotechnol. 2017, 101, 7187-7200.

[10] J. Bosch, M. A. Robien, C. Mehlin, E. Boni, A. Riechers, F. S. Buckner, W. C. Van Voorhis, P. J. Myler, E. A. Worthey, G. DeTitta, J. R. Luft, A. Lauricella, S. Gulde, L. A. Anderson, O. Kalyuzhniy, H. M. Neely, J. Ross, T. N. Earnest, M. Soltis, L. Schoenfeld, F. Zucker, E. A. Merritt, E. Fan, C. L. Verlinde, W. G. Hol, J. Med. Chem. 2006, 49, 5939-5946.

[11] a) J. Becker, M. Brendel, Biol. Chem. Hoppe-Seyler 1996, 377, 357-362; b) W. Uerkvitz, Eur. J. Biochem. 1971, 23, 387-395.

[12] Y. Miyamoto, T. Masaki, S. Chohnan, Biochim. Biophys. Acta 2007, 1774, 1323-1330.

[13] J. Acosta, J. del Arco, S. Martinez-Pascual, V. Clemente-Suárez, J. Fernández-Lucas, Catalysts 2018, 8, 9.

[14] T. C. Bruice, Acc. Chem. Res. 2002, 35, 139-148.

[15] R. Anand, P. A. Kaminski, S. E. Ealick, Biochemistry 2004, 43, 2384-2393.

[16] J. Holguin, R. Cardinaud, Eur. J. Biochem. 1975, 54, 515-520.

[17] O. A. Stasyuk, H. Szatyłowicz, T. M. Krygowski, J. Org. Chem. 2012, 77, 4035-4045.

[18] J. Klett, A. Núñez-Salgado, H. G. Dos Santos, Á. Cortés-Cabrera, A. Perona, R. Gil-Redondo, D. Abia, F. Gago, A. Morreale, J. Chem. Theory Comput. 2012, 8, 3395-3408.

[19] Z. Bikadi, L. Demko, E. Hazai, Arch. Biochem. Biophys. 2007, 461, 225234

[20] A. de Marco, Microb. Cell Fact. 2009, 8, 26

[21] L. P. Jordheim, D. Durantel, F. Zoulim, C. Dumontet, Nat. Rev. Drug Discovery 2013, 12, 447-464.

[22] a) C. M. Galmarini, J. R. Mackey, C. Dumontet, Lancet Oncol. 2002, 3, 415-424; b) W. B. Parker, Chem. Rev. 2009, 109, 2880-2893.

[23] L. L. Bondoc, Jr., G. Ahluwalia, D. A. Cooney, N. R. Hartman, D. G. Johns, A. Fridland, Mol. Pharmacol. 1992, 42, 525-530.

[24] 20th WHO Essential Medicines List (EML), http://www.who.int/medicines/publications/essentialmedicines/en/, March 2017.
[25] F. Huguet, T. Leguay, E. Raffoux, P. Rousselot, N. Vey, A. Pigneux, N. Ifrah, H. Dombret, Leuk. Lymphoma 2015, 56, 847-857.

[26] J. V. Tuttle, M. Tisdale, T. A. Krenitsky, J. Med. Chem. 1993, 36, 119-125.

[27] S. Hammes-Schiffer, S. J. Benkovic, Annu. Rev. Biochem. 2006, 75, 519 541.

[28] C. Mateo, J.M. Palomo, G. Fernández-Lorente, J. M. Guisán, R. Fernández-Lafuente, Enzyme Microb. Technol. 2007, 40, 1451-1463.

[29] R. A. Sheldon, S. van Pelt, Chem. Soc. Rev. 2013, 42, 6223-6235.

[30] J. Fernández-Lucas, A. Fresco-Taboada, C. Acebal, I. de la Mata, M. Arroyo, Appl. Microbiol. Biotechnol. 2011, 91, 317-327.

[31] a) A. Fresco-Taboada, I. Serra, M. Arroyo, J. Fernández-Lucas, I. de la Mata, M. Terreni, Catal. Today 2016, 259, 197-204; b) A. Fresco-Taboada, I. Serra, J. Fernandez-Lucas, C. Acebal, M. Arroyo, M. Terreni, I. de la Mata, Molecules 2014, 19, 11231-11249.

[32] C. N. Britos, M. J. Lapponi, V. A. Cappa, C. W. Rivero, J. A. Trelles, J. Fluorine Chem. 2016, 186, 91-96.

[33] G. Hollermann, R. Dhekane, S. Kroll, K. Rezwan, Biochem. Eng. J. 2017 126, 30-39.

[34] E. A. Manoel, M. Pinto, J. C. S. dos Santos, V. G. Tacias-Pascacio, D. M. G. Freire, J. C. Pinto, R. Fernandez-Lafuente, RSC Adv. 2016, 6, 6281462824.

[35] H. Ohshima, in Electrical Phenomena at Interfaces and Biointerfaces: Fundamentals and Applications in Nano-, Bio-, and Environmental Sciences (Ed.: H. Ohshima), John Wiley \& Sons, Inc. , Hoboken, NJ, USA, 2012, pp. 27-34

[36] U. K. Laemmli, Nature 1970, 227, 680-685.

[37] S. C. Gill, P. H. von Hippel, Anal. Biochem. 1989, 182, 319-326.

[38] P. H. Brown, P. Schuck, Biophys. J. 2006, 90, 4651-4661.

[39] K. E. Van Holde, Physical Biochemistry, 2nd ed., Prentice-Hall, Englewood Cliffs, NJ, 1985.

[40] D. A. Case, J. T. Berryman, R. M. Betz, D. S. Cerutti, I. T. E. Cheatham, T. A. Darden, R. E. Duke, T. J. Giese, H. Gohlke, A. W. Götz, N. Homeyer, S. Izadi, P. Janowski, J. Kaus, A. Kovalenko, T. S. Lee, S. LeGrand, P. Li, T. Luchko, R. Luo, B. Madej, K. M. Merz, G. Monard, P. Needham, H. Nguyen, H. T. Nguyen, I. Omelyan, A. Onufriev, D. R. Roe, A. Roitberg, R. Salomon-Ferrer, C. L. Simmerling, W. Smith, J. Swails, R. C. Walker, J. Wang, R. M. Wolf, X. Wu, D. M. York, P. A. Kollman, AMBER 14, University of California, San Francisco, 2015.

[41] R. Salomon-Ferrer, A. W. Götz, D. Poole, S. Le Grand, R. C. Walker, J. Chem. Theory Comput. 2013, 9, 3878-3888.

[42] P. A. Sánchez-Murcia, A. Cortés-Cabrera, F. Gago, J. Comput.-Aided Mol. Des. 2017, 31, 915-928.

[43] A. Morreale, R. Gil-Redondo, A. R. Ortiz, Protein Sci. 2007, 67, 606-616. [44] I. K. McDonald, J. M. Thornton, J. Mol. Biol. 1994, 238, 777-793.

Manuscript received: May 12, 2018

Accepted Article published: July 18, 2018

Version of record online: August 9, 2018 